Research Article

\title{
Distribution Features of the Minimum Rock Cover Thickness of the Surrounding Rock Self-Stability of the Metro Tunnel in the Soil-Rock Dualistic Stratum
}

\author{
Ziguang Zhang $\mathbb{D}^{1},{ }^{1}$ Tao $\mathrm{Xu}^{2}{ }^{2}$ Guangyong Cao ${ }^{D},{ }^{1}$ and Xiaofeng Liu ${ }^{2}$ \\ ${ }^{1}$ Anhui Province Key Laboratory of Building Structure and Underground Engineering, Anhui Jianzhu University, Hefei, China \\ ${ }^{2}$ Anhui Sijian Holding Group Co., Ltd., Hefei, China
}

Correspondence should be addressed to Ziguang Zhang; phdzzg@ahjzu.edu.cn

Received 1 November 2019; Revised 28 January 2020; Accepted 27 March 2020; Published 8 July 2020

Academic Editor: Flavio Stochino

Copyright ( 92020 Ziguang Zhang et al. This is an open access article distributed under the Creative Commons Attribution License, which permits unrestricted use, distribution, and reproduction in any medium, provided the original work is properly cited.

Based on the maximum value of the self-stability of surrounding rock, the key issues affecting the distribution of the minimum mock cover thickness of the surrounding rock self-stability (MRCT-SRS) of the metro tunnel in the soil-rock dualistic stratum are discussed. The MRCT-SRS was studied for different soft stratum thicknesses $H s$ and excavation spans $D$ based on cusp catastrophe theory. Moreover, the 3D spatial distribution was determined, and the fitted curves were constructed according to the MRCT-SRS, $H s$, and $D$. This facilitated the assessment of the stability of the surrounding rock in the excavation of a metro tunnel. Combined with the construction practices used for the Qingdao metro project, the validity of the obtained MRCT-SRS has been verified by the inverse analysis of the monitored data from the metro tunnel. Furthermore, the application of the MRCT-SRS in determining the reasonable buried depth of a metro line has been explored. The research results have provided theoretical support and scientific basis for the preparation, revision, and improvement of the relevant codes, standards, and guidelines for metro tunnel planning and design.

\section{Introduction}

The fundamental goal of an excellent metro tunnel design scheme is to make full use of the self-stability of the surrounding rock. Recently, many subsurface metro tunnels have been carried out in the soil-rock dualistic stratum in cities, such as Qingdao [1], Dalian [2], Guangzhou [3], Chongqing [4], and Guiyang [5]. When a metro tunnel is excavated in the urban area where the buried depth of the bedrock is shallow and the soft soil stratum thickness is thin, the tunnel should be placed in the rock stratum and maintained such that the minimum rock cover thickness meets the requirements of the self-stability of the rock surrounding. In this case, the construction of a metro tunnel can greatly reduce the tunnel support measures, save construction costs, reduce the tunnel construction safety risk and construction difficulty, and reduce the impact on the surrounding environment.
Many scholars have studied the relationship between the stability of the surrounding rock and the rock cover thickness. Sun et al. [1] used an example of a metro station in Qingdao to determine the safety factor of a tunnel in surrounding rock at different buried depths by using the strength reduction method. They also considered the safety factor equal to 1 as the basis for judging the surrounding rock self-stability of the metro tunnel and determined the relationship between the minimum rock cover thickness and the soil stratum thickness. Yang and Xiao [6] established the cusp catastrophe model of the safety thickness of a karst tunnel floor and derived the expression for the critical safety thickness. Xu et al. [7] designed a study based on the Qingdao Jiaozhou Bay Subsea Tunnel using two mutually verified discrimination methods: the minimum vertical displacement of the tunnel vault and the maximum safety factor of the tunnel surrounding rock. They then studied the minimum rock cover thickness of the subsea tunnel and 


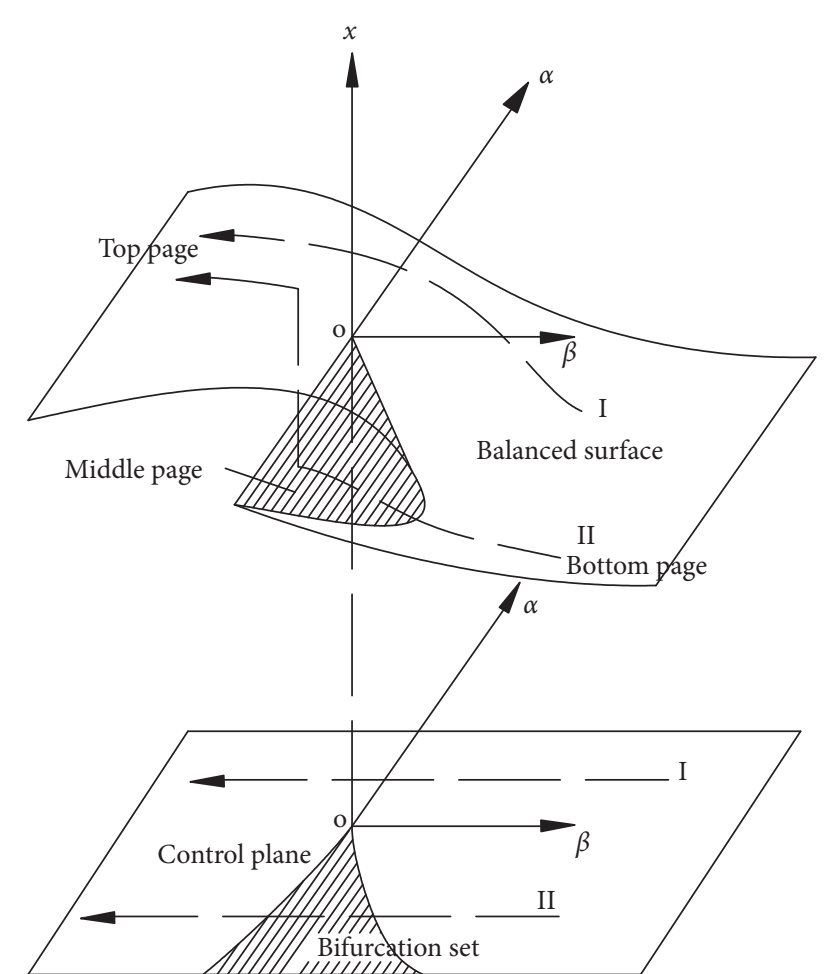

Figure 1: Balance-curved surface and bifurcation set of the cusp catastrophe mode.

considered that the minimum rock cover thickness of a subsea tunnel is the reasonable and effective thickness of the tunnel. Wang et al. [8] pointed out that the reasonable buried depth of the metro station in the soil-rock dualistic stratum should be determined by using the double index system of the overburden thickness-span ratio and the rock cover thickness-span ratio and noted that the rock cover thickness-span ratio is more sensitive to the safety of tunnel construction than the overburden thickness-span ratio. Qiu et al. [9] studied the relationship between the minimum rock cover thickness and the surrounding rock stability of the subsea tunnel by the numerical method. Zhang et al. [10] discussed and expounded upon the issues of the surrounding rock self-stability of the metro tunnel in the soil-rock dualistic stratum from the three aspects of the stress, the displacement, and the safety factor. Wang et al. [11] studied the conversion timing of tunnel excavation method in upper soft and lower hard strata based on displacement direction angle theory under different working conditions.

The catastrophe theory was put forward by Thom, a French scholar, in the 1970s [12] and was then expanded into a perfect system by Trotman and Zeeman [13], Zeeman et al. [14], and Poston and Stewart [15]. Catastrophe theory is a mathematical method used to study the phenomenon of discontinuity in nature. The cusp catastrophe model is one of seven primary catastrophe models in catastrophe theory, which has been widely used in the study of tunnel surrounding rock stability, and it has achieved ideal results [16-22]. Xia et al. [16] used cusp catastrophe theory and the discontinuous deformation analysis method to study the

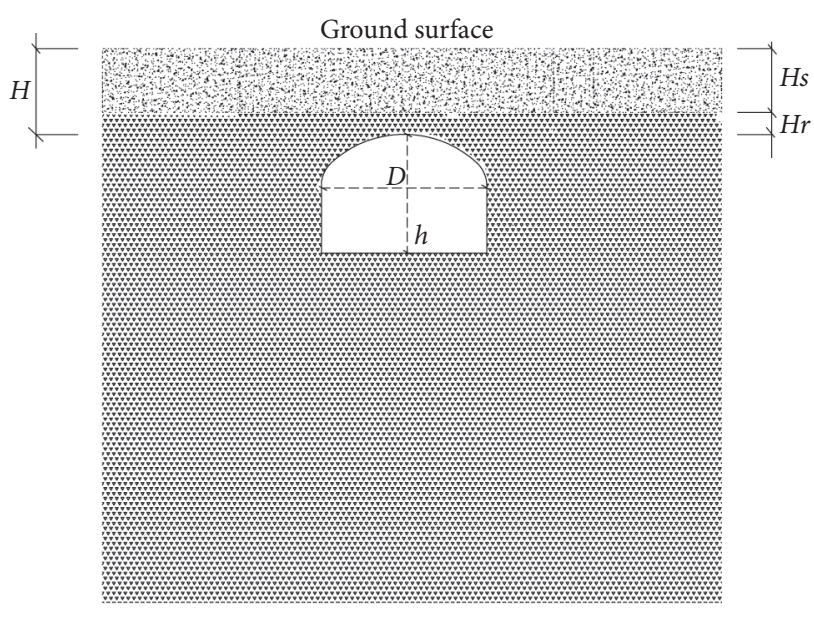

Figure 2: Analysis model.

stability of the tunnel surrounding rock and obtain the safety factor. Based on the measured deformation data of the surrounding rock, Ren et al. [17] established the catastrophe model of the tunnel surrounding rock cusp by using catastrophe theory and deduced the instability criterion of the surrounding rock. Wang et al. [18] used the cusp catastrophe model to study the stability of gas storage pillars in layered salt caverns. Zhang and Han [19] used catastrophe theory to study the collapse mechanism and possible collapse block shape of a shallow, unlined tunnel. Zhou [20] et al. established a model based on the cusp catastrophe theory and analyzed the stability of the support system in the goaf of room pillar gypsum. Zhang et al. [21] and Huang and Zhang [22] used catastrophe theory to study the instability mechanism of a shallow tunnel.

The problem of the minimum mock cover thickness of the surrounding rock self-stability (MRCT-SRS) of the tunnel has been studied by many scholars, who have used numerical calculations to analyze the stress, the deformation, and the safety factor. However, based on cusp catastrophe theory, rarely no relevant report has been found on the MRCT-SRS of the metro tunnel in the soil-rock dualistic stratum. This paper based on the calculation and analysis of the MRCT-SRS under different soft stratum thickness $H s$ and excavation span $D$ was studied based on cusp catastrophe theory and numerical calculation, the $3 \mathrm{D}$ spatial distribution was drawn, and the fitted curves was constructed among MRCT-SRS, $H s$, and $D$, which facilitated the assessment on the stability of the surrounding rock in excavation of metro tunnel. Combined with the construction practice of Qingdao metro project, the validity of the obtained MRCT-SRS has been verified by the inverse analysis on the data monitored for metro tunnel, and the application of MRCT-SRS in determining the reasonable buried depth of metro line has been expounded. The research results can provide theoretical support for the design of reasonable depth of the vertical section of metro tunnel in soil-rock dualistic stratum and further offer a scientific basis for the preparation, revision, and improvement of relevant codes, standards, and guidelines. 
TABLE 1: The physical and mechanical parameters.

\begin{tabular}{lccccc}
\hline Types of stratum & Cohesion $(\mathrm{MPa})$ & Internal friction angle $\left(^{\circ}\right)$ & Modulus of elasticity $(\mathrm{GPa})$ & Poisson's ratio & Density $\left(\mathrm{kg} / \mathrm{m}^{3}\right)$ \\
\hline Soft soil stratum & 0.032 & 20 & 0.05 & 0.38 & 22.5 \\
Rock stratum & 0.60 & 35 & 5.0 & 0.25 & 24.5 \\
\hline
\end{tabular}

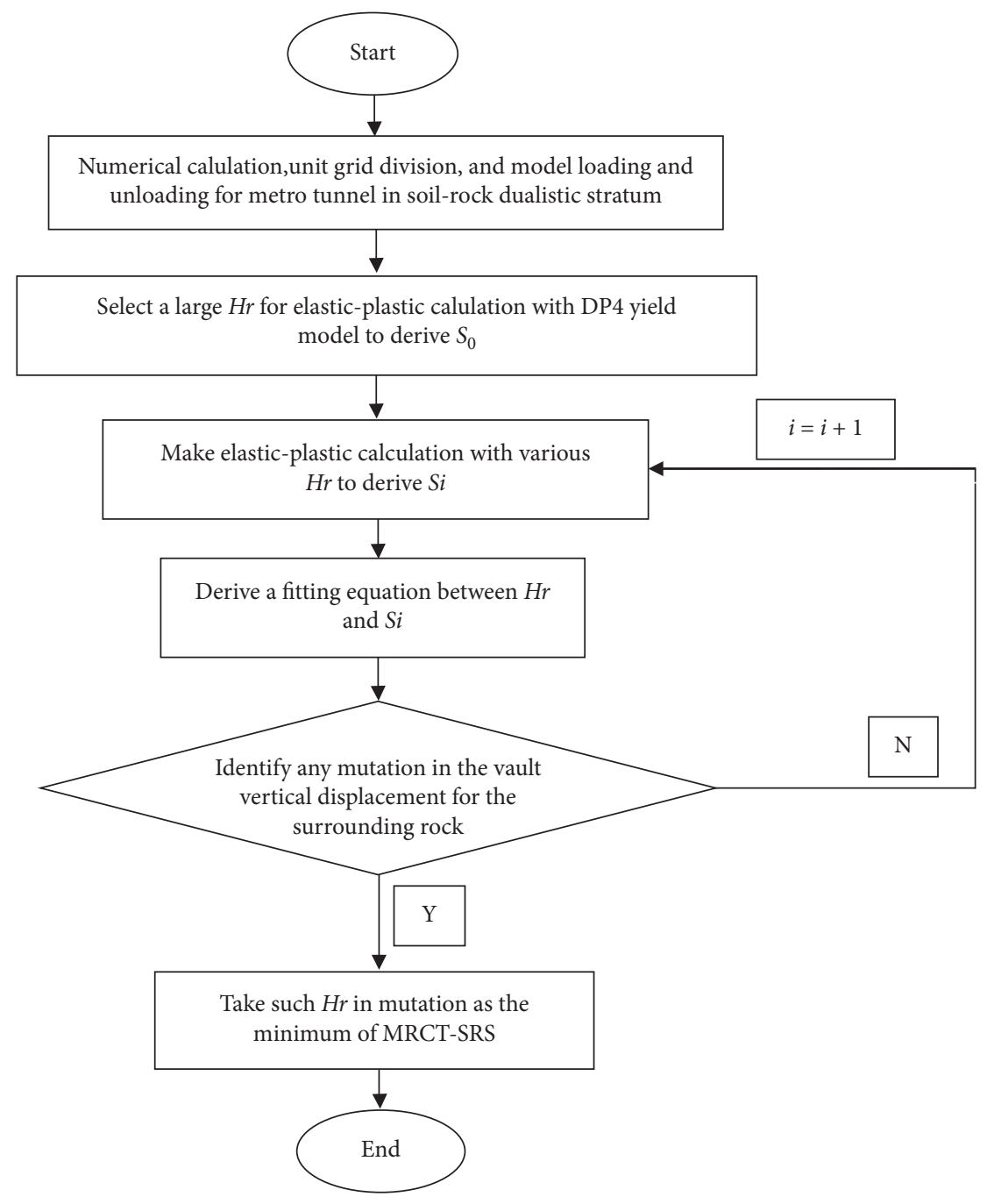

FiguRE 3: MRCT-SRS calculation process for metro tunnel.

\section{Methodology and Research Process}

2.1. Cusp Catastrophe Theory. The cusp catastrophe model uses the simplest catastrophe mode with lag, divergence, and other behaviors, which is unique to the high-order catastrophe model. The critical interface is easy to construct and has a strong geometric rationale. Of the seven primary catastrophe models used in catastrophe theory, the cusp catastrophe model is the one with the most extensive application [23-29].

The potential function $\mathrm{V}$ of the cusp catastrophe model is a 3D space $(x, u, v)$ composed of the control variables $u$ and $v$ and the state variable $x$ as follows:

$$
V(x)=x^{4}+u x^{2}+v x
$$

An equation for the cusp catastrophe model for the balanced curved surface has been obtained after first deriving the potential function (1) with respect to $x$ as follows:

$$
V \dot{(x)}=4 x^{3}+2 u x+v .
$$

The cusp catastrophe model uses a continuous balanced surface with a 3D phase space, the interior of which is folded into upper, middle, and lower pages, as shown in Figure 1. Different areas have different numbers of balance points. On the middle page, the balance point falls on the maximum value of the potential function, so it is unstable. However, on the upper and lower pages, the potential function takes its minimum value, so the balance point is stable. The boundary between the upper and lower pages, on the one hand, and the 


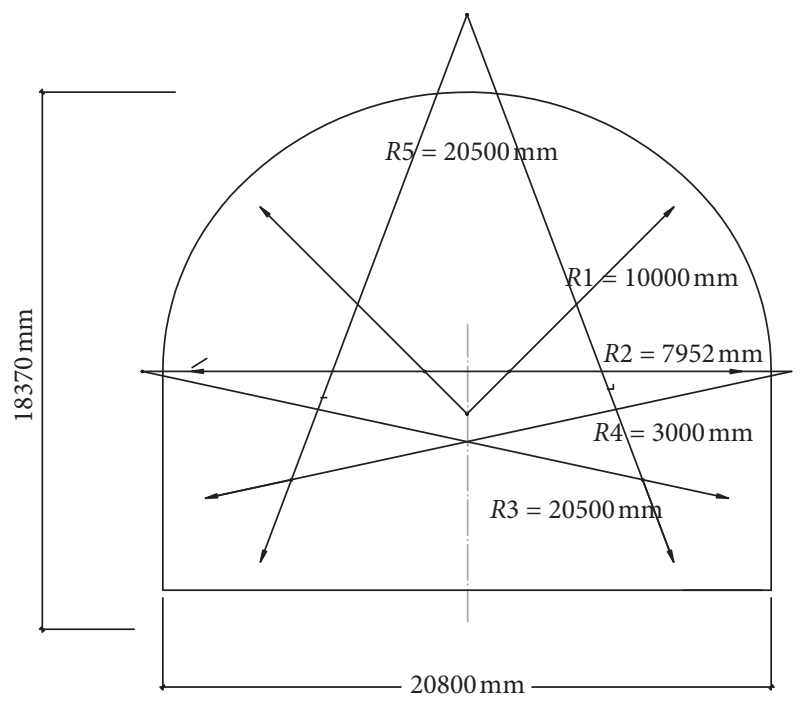

Figure 4: Section size.

middle page, on the other hand, is composed of points with vertical tangents, which is a set of mutation points as follows:

$$
V \ddot{(x)}=12 x^{2}+2 u \text {. }
$$

Combining formulas (2) and (3) results in a bifurcation set, which is the projection of the fold of the balance-curved surface in the $\mathrm{u}-\mathrm{v}$ plane as follows:

$$
\Delta=8 u^{3}+27 v^{2} \text {. }
$$

When applying catastrophe theory, scholars have used formula (4) as a direct criterion to determine the cusp mutation. When $\Delta>0$, the system is in a stable state; when $\Delta=0$, the system is in a critical equilibrium state; when $\Delta<0$, the system is in an unstable state [6].

2.2. Analysis Model. See Figure 2, for the analysis model of the MRCT-SRS of the metro tunnel in the soil-rock dualistic stratum. In the figure, $H$ represents the buried tunnel depth; $D$, the excavation span; $h$, the excavation height; and $H s$ and $H r$, respectively, the soft soil stratum thickness and the rock cover thickness.

A statistical analysis was performed of the geotechnical test results of 3227 geological boreholes in nearly 2000 sets of soil-rock strata along the Qingdao metro tunnel. Accordingly, the values of the physical and mechanical parameters of the soft soil stratum and the rock stratum in the soil-rock dualistic stratum structure are shown in Table 1 .

2.3. Target. The vault is the point at which the deflection is the largest around the cavern of the shallow metro tunnel. Therefore, the vertical displacement of the vault is the key indicator when evaluating the stability of the surrounding rock of the tunnel $[30,31]$. If the rock cover thickness is large over the vault of the tunnel in the soil-rock dualistic stratum and it is gradually reduced, the vertical displacement of the vault at first is slowly reduced. Then, the displacement gradually increases after reaching its minimum as the
TABLE 2: Calculation results of the vault vertical displacement.

\begin{tabular}{lccccccc}
\hline$H r(\mathrm{~m})$ & 12 & 11 & 10 & 9 & 8 & 7 & 6 \\
\hline $\mathrm{S}(\mathrm{mm})$ & 4.325 & 4.122 & 4.160 & 4.249 & 4.350 & 4.530 & 5.018 \\
$\mathrm{Hr}(\mathrm{m})$ & 5 & 4 & 3 & 2 & 1.5 & 1.4 & 1 \\
$\mathrm{~S}(\mathrm{~mm})$ & 5.437 & 6.107 & 7.287 & 10.224 & 14.660 & 16.288 & 26.149 \\
\hline
\end{tabular}
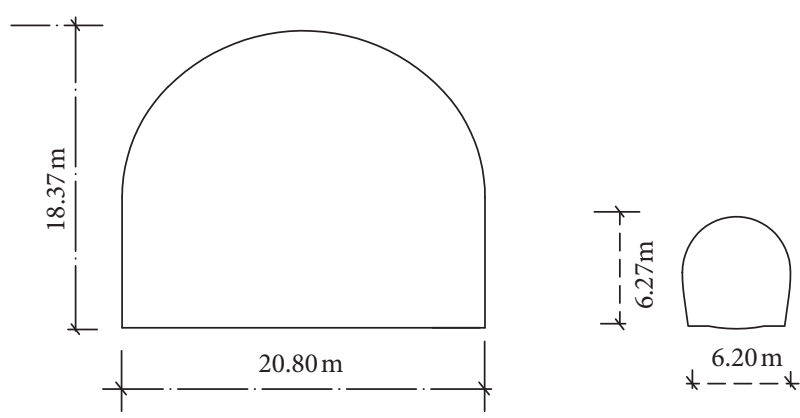

FIGURE 5: Metro tunnel section type and size.

thickness continues to decrease. When the thickness decreases to a certain value, the displacement sharply rises [7]. Currently, the vertical displacement of the tunnel vault is selected as the target for evaluating the self-stability of the surrounding rock of the tunnel. Furthermore, the corresponding rock cover thickness at the mutation point is used as the MRCT-SRS of the tunnel.

2.4. Process. For the MRCT-SRS of the metro tunnel in the soil-rock dualistic stratum based on featured point displacement in cusp catastrophe theory, the calculation is performed as follows:

(1) First, a numerical calculation model is constructed of the metro tunnel in the soil-rock dualistic stratum. In the numerical calculation, the stratum is considered according to the plane strain of ideal elastic-plastic materials, which should conform to the Mohr-Coulomb strength criterion and the large deformation hypothesis. ANSYS numerical calculation software and the inscribed circle DP4 yielded criterion based on the Mohr-Coulomb conditions, which were adopted for the one-time excavation of the whole section without considering the influence of groundwater and other factors. The upper boundary of the calculation model is set at the ground surface, and the lower boundary is set from the vault bottom of the excavation section down to 3.5 times the excavation height. Moreover, the distance between the left and right boundaries is more than 7 times the excavation span. The initial geostress incorporates not only the gravity stress of the rock and soil but also a uniformly distributed load of $20 \mathrm{kPa}$ imposed on the ground surface. A large deformation mode is used during the calculation. The failure of the surrounding rock by large deformation can be reproduced by updating the coordinates. The vertical and horizontal ranges of the unit grid around 
TABLE 3: MRCT-SRS calculation results for metro tunnel.

\begin{tabular}{llcccccccccc}
\hline$H s(\mathrm{~m})$ & & 3 & 6 & 9 & 12 & 15 & 18 & 21 & 24 & 27 & 30 \\
\hline \multirow{2}{*}{ MRCT-SRS (m) } & Station tunnel & 0.62 & 0.92 & 1.17 & 1.45 & 1.76 & 2.02 & 2.28 & 2.58 & 2.92 & 3.12 \\
& Runing tunnel & 0.20 & 0.34 & 0.45 & 0.52 & 0.59 & 0.71 & 0.78 & 0.90 & 0.97 & 1.13 \\
\hline
\end{tabular}

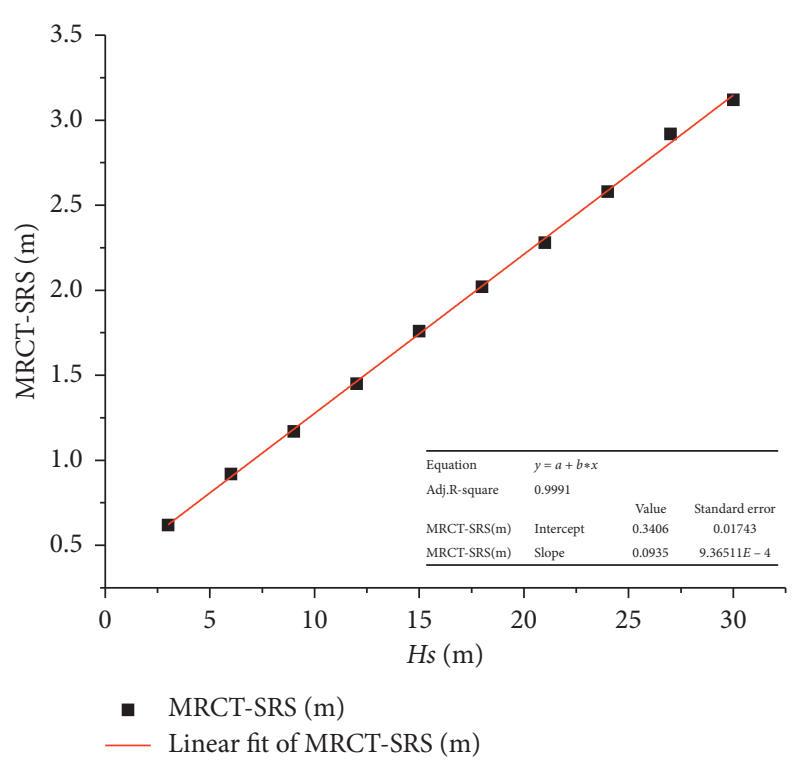

(a)

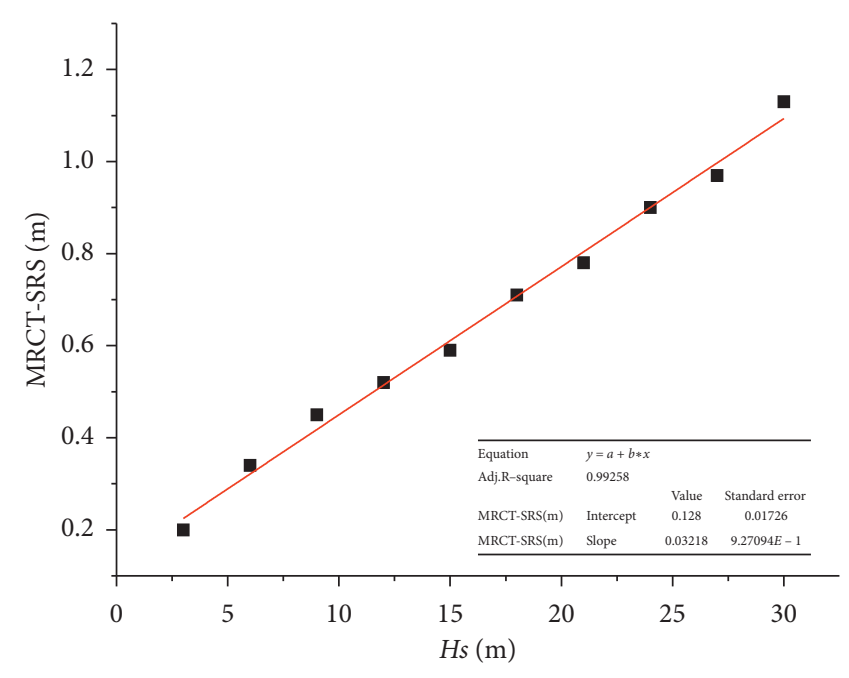

- MRCT-SRS (m)

_ Linear fit of MRCT-SRS (m)

(b)

FIgUre 6: Metro tunnel MRCT-SRSs change with respect to Hs. (a) Station tunnel. (b) Running tunnel.

the tunnel are $0.5 \mathrm{~m}$, and those of the more peripheral unit grid are set at $1.0 \mathrm{~m}$.

(2) By continuous calculations, the rock cover thickness is determined with respect to the smallest vault vertical displacement of the tunnel surrounding rock as the thickness gradually increases. Then, the thickness is reduced gradually at a specific interval (e.g., $1.0 \mathrm{~m}$ or $0.5 \mathrm{~m}$ ) for multiple calculations. The vertical displacements $S i$ of the tunnel vault in each calculation are recorded to derive a sequential $\mathrm{Si}-\mathrm{Hr}$ curve between the displacement $\mathrm{Si}$ and the rock cover thickness $H r$. The number of calculations should increase in the mutation part of the $\mathrm{Si}-\mathrm{Hr}$ curve.

(3) The calculation should begin starting with the rock cover thickness with respect to the smallest vault vertical displacement of the tunnel surrounding rock as the thickness gradually increases. The end interpolation method is used to fit the data of vertical displacement $S$ and overburden rock thickness $\mathrm{Hr}$, producing a quartic function as follows:

$$
S=a_{0}+a_{1} H r+a_{2} H r^{2}+a_{3} H r^{3}+a_{4} H r^{4}
$$

where $a_{0}, a_{1}, a_{2}, a_{3}$, and $a_{4}$ are undetermined coefficients.

(4) The fitting equation is transformed, and the standard potential function of the cusp mutation is derived as

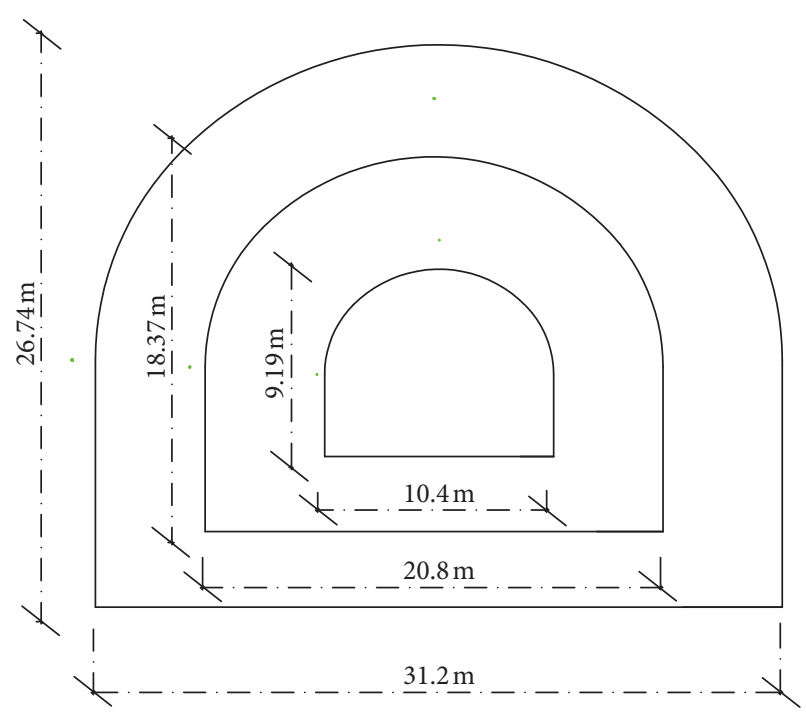

FIGURE 7: Metro tunnel excavation section.

$V(x)=x^{4}+u x^{2}+v x$, for which $u=\left(a_{2} / a_{4}\right)-$ $\left(3 a_{3}^{2} / 8 a_{4}^{2}\right)$ and $v=\left(a_{1} / a_{4}\right)-\left(a_{2} a_{3} / 2 a_{4}^{2}\right)+\left(a_{3}^{3} / 8 a_{4}^{3}\right)$.

(5) The bifurcation set equation is derived as $\Delta=8 u^{3}+$ $27 v^{2}$ according to cusp catastrophe theory.

In this research, $H r$ with respect to $\Delta=8 u^{3}+27 v^{2}=0$ is selected as the MRCT-SRS. Its calculation is shown in Figure 3. 
TABLE 4: MRCT-SRS for the metro tunnel.

\begin{tabular}{lcccccc}
\hline$H s(\mathrm{~m})$ & & 6 & 12 & 18 & 24 & 30 \\
\hline \multirow{2}{*}{ MRCT-SRS (m) } & $D=10.4 \mathrm{~m}$ & 0.31 & 0.78 & 1.27 & 1.48 & 1.83 \\
& $D=31.2 \mathrm{~m}$ & 1.23 & 2.24 & 3.06 & 3.77 & 4.42 \\
\hline
\end{tabular}

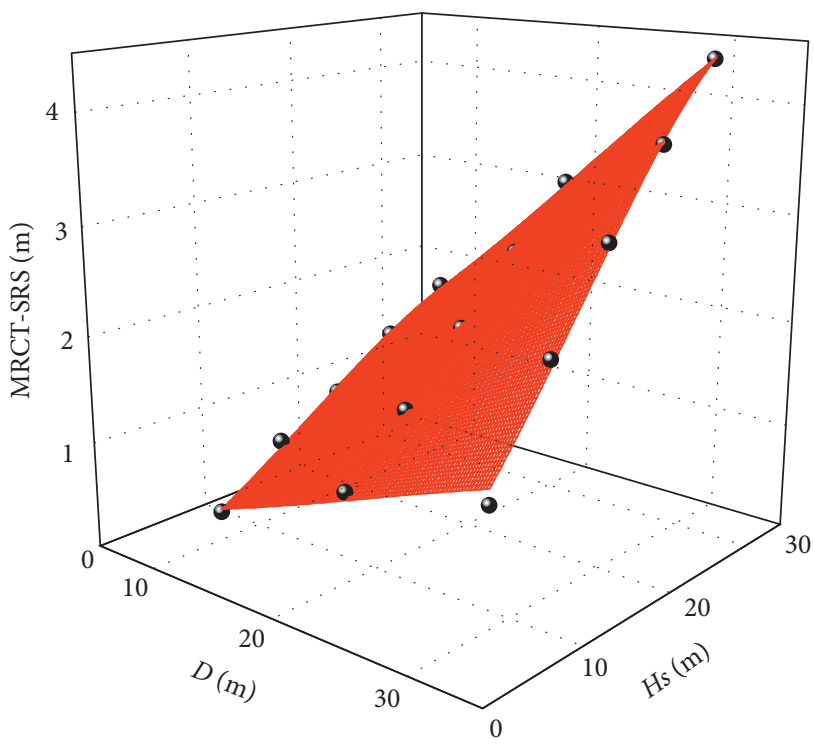

FIgURE 8: 3D MRCT-SRS $\sim \mathrm{Hs} \sim \mathrm{D}$ diagram for metro tunnel.

2.5. Example Analysis. The MRCT-SRS calculation is demonstrated in detail in the following example of a metro tunnel with soft soil stratum thickness Hs of $12 \mathrm{~m}$. The shape and dimensions of the tunnel section are shown in Figure 4. The calculation results of the vertical displacement $S i$ under different $\mathrm{Hr}$ values are shown in Table 2.

The data of $S$ and $H r$ are used, so $H r$ is set to $11 \mathrm{~m}$ to perform the polynomial fitting. When $H r$ is $1 \mathrm{~m}$, the fitting is carried out on 11 sets of data with $H r$ vales from $1 \mathrm{~m}$ to $11 \mathrm{~m}$, producing the result as follows:

$$
\begin{aligned}
S= & 47.75224+28.81764 H r+6.90942 H r^{2} \\
& +0.69678 H r^{3}+0.02495 H r^{4} .
\end{aligned}
$$

Substitute the values of the four parameters of $a_{1} \sim a_{4}$ from formula (6) into formulas (1) and (4). The result is $u=$ -15.5395 and $v=10.69658$.

$\Delta=-26929.91153<0$, indicating that $H r$ does not meet the MRCT-SRS requirements.

When $H r$ is $2 \mathrm{~m}, \Delta=1195349.531>0$, indicating that it meets the requirements. Therefore, the MRCT-SRS should be between $1 \mathrm{~m}$ and $2 \mathrm{~m}$.

To improve further the calculation accuracy of the MRCT-SRS, $\mathrm{Hr}$ is set as $1.5 \mathrm{~m}$. The result shows $\Delta=7211.982>0$, indicating that the $H r$ meets the requirements; when $\mathrm{Hr}$ is $1.4, \Delta=-3072.25<0$, indicating that it does not meet the requirements. Therefore, the MRCT-SRS should be between $1.4 \mathrm{~m}$ and $1.5 \mathrm{~m}$. The MRCTSRS is finally set at $1.45 \mathrm{~m}$ when the soft soil stratum thickness is $12 \mathrm{~m}$ in this paper.

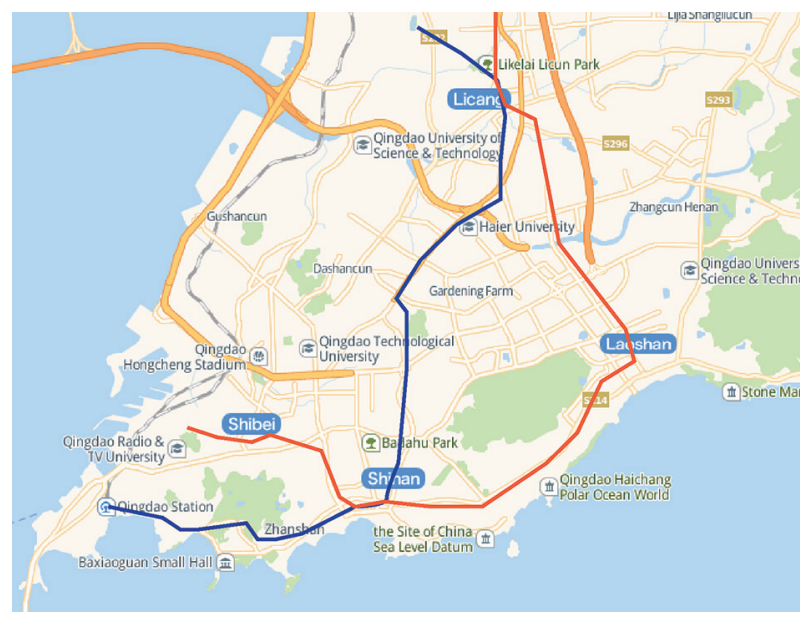

- Line 3

L Line 2

FIgURE 9: Qingdao metro lines 2 and 3 plane map.

\section{Distribution Features of the MRCT-SRS}

3.1. MRCT-SRSs of the Metro Station Tunnel and the Running Tunnel. The example of the engineering of the Qingdao metro tunnel is used in this research to investigate the MRCT-SRS of the station tunnel and the running tunnel with two main types of sections in a soil-rock dualistic stratum (see Figure 5).

The results of the MRCT-SRS calculations for the metro station tunnel and the running tunnel under different soft soil stratum thicknesses $H s$ are shown in Table 3 and Figure 6. The MRCT-SRS of the metro tunnel approximately linearly increases or decreases with respect to Hs. The linearity fitting is used to predict the MRCT-SRSs of the metro station and the running tunnel. The fitted equation for the station tunnel MRCT-SRS and $H s$ is shown in formula (7). The adjusted R-square value is 0.9991 , and the MRCT-SRS is approximately linear along with $H s$. The fitted equation of the running tunnel MRCT-SRS and $H s$ is shown in formula (8), and the adjusted R-square value is 0.99258 . With formulas (7) and (8), the MRCT-SRSs for the station tunnel and the running tunnel can be derived with respect to different Hs.

The MRCT-SRS of the metro tunnel increases approximately linearly with the increase in $H s$. This result occurs because, when excavating the metro tunnel in the soil-rock dualistic stratum under the requirements of the MRCT-SRS, the overlying soft soil stratum bears a higher load, while the rock cover stratum bears more of the structure. The rock mechanics performance around the tunnel is similar to the force mode of a composite arch or a composite beam. Therefore, when the $H s$ is greater, the corresponding load and the MRCT-SRS become larger.

Station tunnel: MRCT - SRS $=0.0935 H s+0.3406$,

Running tunnel: MRCT - SRS $=0.03218 H s+0.128$. 
TABLE 5: Qingdao metro station tunnel in excavation.

\begin{tabular}{|c|c|c|c|c|}
\hline $\mathrm{S} / \mathrm{N}$ & Station name & Excavation technique & $D(\mathrm{~m}) \times h(\mathrm{~m})$ & $H(\mathrm{~m})$ \\
\hline 1 & Qingdao Railway Station & Open-cut + CRD & $23.45 \times 14.58$ & $2.3 \sim 8.5$ \\
\hline 2 & Zhongshan Park & Arch cover method & $19.20 \times 16.20$ & $10.0 \sim 12.0$ \\
\hline 3 & Zhanshan & Arch cover + CRD & $20.52 \times 18.18$ & $13.0 \sim 15.1$ \\
\hline 4 & Jiangxi Rd & Arch cover + CRD & $20.60 \times 15.50$ & $8.9 \sim 10.5$ \\
\hline 5 & Dunhua Rd & Bench method & $10.38 \times 9.50$ & $14.6 \sim 20.0$ \\
\hline 6 & Qingjiang Rd & Arch cover + CRD & $20.36 \times 17.35$ & $6.3 \sim 8.3$ \\
\hline 7 & Wannianquan Rd & Arch cover + CRD & $20.66 \times 18.16$ & $5.1 \sim 10.1$ \\
\hline 8 & Junfeng Rd & Arch cover + CRD & $20.79 \times 18.37$ & $7.4 \sim 15.6$ \\
\hline 9 & Yan'anlu Rd & Arch cover method & $23.76 \times 19.13$ & $13.4 \sim 16.4$ \\
\hline 10 & Zhiquan Rd & Arch cover method & $23.76 \times 19.13$ & $13.2 \sim 17.0$ \\
\hline 11 & Haichuan Rd & Step + CD & $22.66 \times 16.80$ & $13.3 \sim 19.0$ \\
\hline 12 & Xujia Maidao & Step + CD & $22.10 \times 16.80$ & $13.3 \sim 18.0$ \\
\hline 13 & Tong'an Rd & Arch cover method & $19.80 \times 16.50$ & $8.96 \sim 10.3$ \\
\hline 14 & East Bus Station & Arch cover method & $22.96 \times 16.99$ & $10.8 \sim 11.75$ \\
\hline 15 & Zaoshan Rd & Arch cover method & $19.80 \times 16.50$ & $10.17 \sim 16.22$ \\
\hline 16 & Licun Park & Arch cover + CRD & $24.40 \times 16.80$ & $10.0 \sim 13.0$ \\
\hline Note & & agram method, and & enter diagram $\mathrm{m}$ & \\
\hline
\end{tabular}

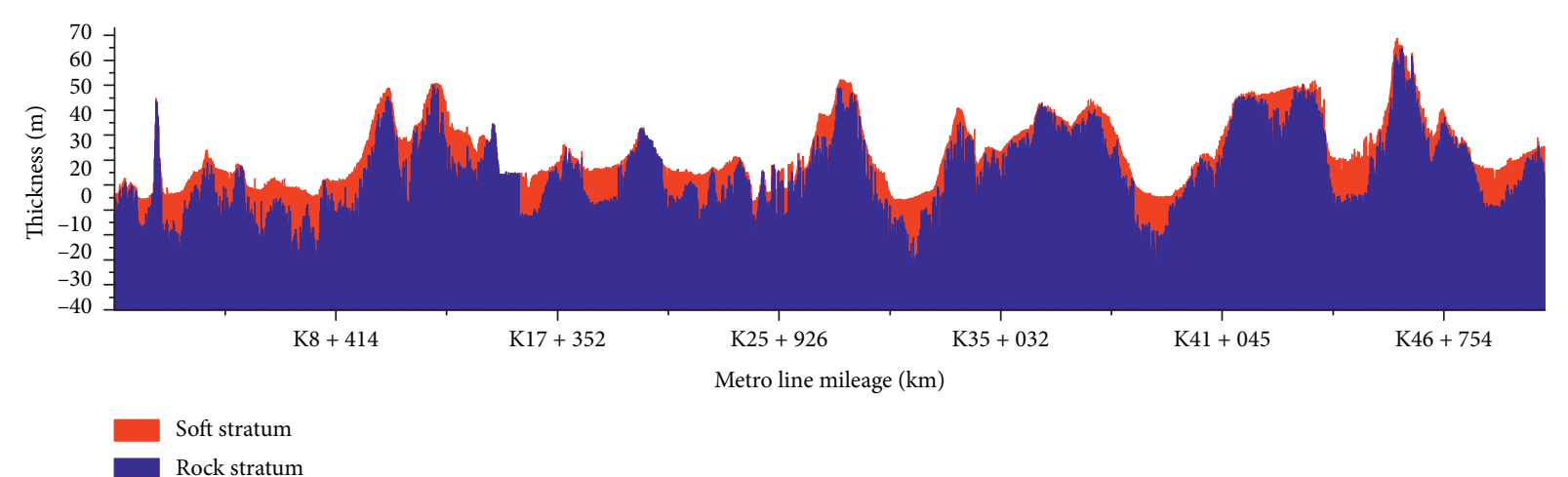

Figure 10: Distribution map of the dualistic stratum structure along the lines.

\subsection{Discussion of How MRCT-SRS Works for the Metro} Tunnel. The stability characteristics of the tunnel surrounding rock are closely related to the shape and size of the tunnel section. By focusing on the metro station tunnel, the general rule of how the MRCT-SRS varies with the excavation span $D$ is discussed in the present study while maintaining the original section shape and high-span ratio but using only the scaling tunnel section size. The tunnel section size is shown in Figure 7. The MRCT-SRS calculation results of the metro tunnel are shown in Table 4 when excavation spans $D$ are $10.4 \mathrm{~m}$ and $31.2 \mathrm{~m}$ with respect to $H s$.

The 3D spatial distribution of MRCT-SRS $\sim \mathrm{H} s \sim \mathrm{D}$ among the metro tunnel MRCT-SRS, soft soil stratum thickness $H s$, and excavation span $D$ is shown in Figure 8. The figure overly shows the distribution characteristics of the metro tunnel MRCT-SRS with respect to different $H s$ and $D$. At the same time, according to the figure, the surrounding rock stability and supplementary measures in the excavation for the metro tunnel in the soil-rock dualistic stratum can be determined as follows:

(1) When $H r$ falls below the interface plane, the excavation for the surrounding rock cannot meet the selfstability condition. Strong supplementary engineering measures are needed to prevent its instability to ensure normal tunnel excavation.

(2) When $H r$ falls on the interface plane, the excavation of the surrounding rock just meets the self-stability condition. Some supplementary engineering measures are needed to prevent its instability to ensure normal tunnel excavation.

(3) When $H r$ falls above the interface plane, the excavation for the surrounding rock can meet the self-stability condition. Only simple supplementary engineering measures are needed to prevent the geometric instability of rocks to ensure normal tunnel excavation.

The fitting equation of MRCT-SRS $\sim \mathrm{Hs} \sim$ Dis shown as formula (9), and the adjusted R-square is 0.99597. By this formula, the MRCT-SRS with respect to different $H s$ and $D$ can be derived:

$$
\begin{aligned}
\mathrm{MRCT}-\mathrm{SRS} & =-0.59406+6.8447 \\
& \exp \left[-\frac{(D-51.83602)^{2}}{1742.17836}-\frac{(\mathrm{Hs}-38.31975)^{2}}{1037.83038}\right] .
\end{aligned}
$$




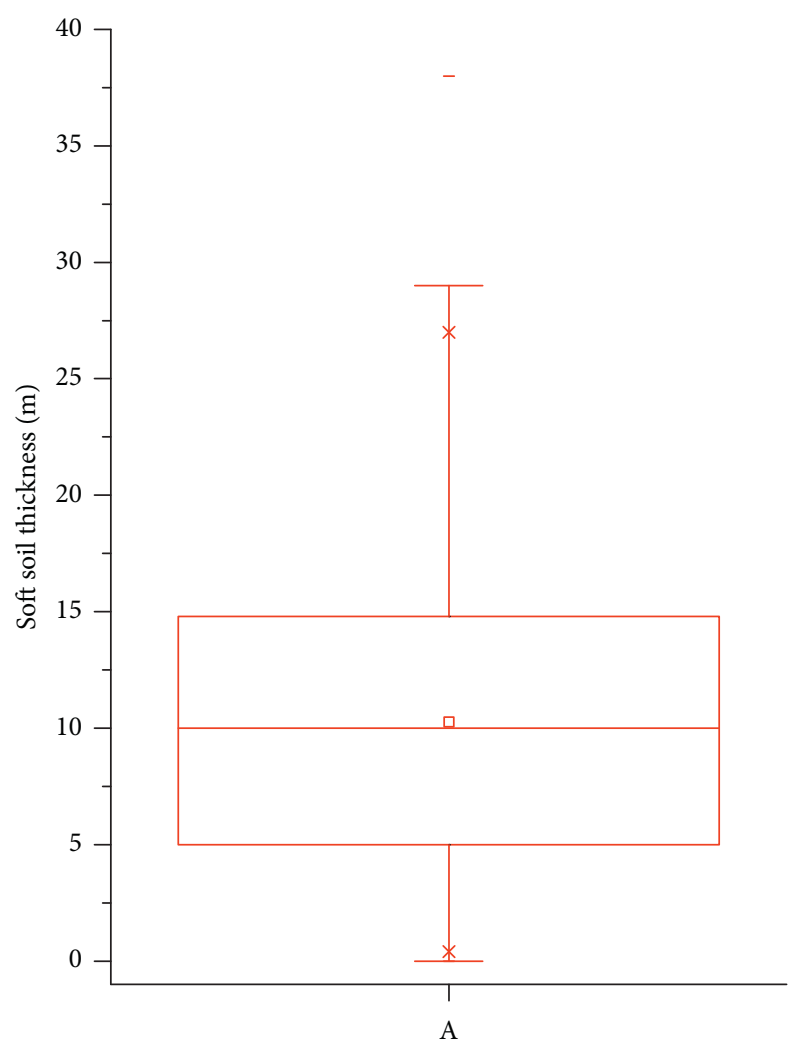

FIGURE 11: Statistical box diagram of the soft soil thickness along lines.

\section{Case Analysis and Engineering Application}

\subsection{Project Overview}

4.1.1. Project Descriptions. The planned metro lines for Qingdao's rail transit are approximately $807 \mathrm{~km}$ long and occur in 16 lines. Qingdao Metro Line 3, the first urban rail transit construction, is approximately $24.8 \mathrm{~km}$ long and includes 22 stations. Its construction is followed by Line 2, covering a length of approximately $25.2 \mathrm{~km}$ with 22 stations. The two lines have 16 underground excavated stations. Except for Dunhua Road Station in the tower-column structure, the other excavated stations all adopt a single-arch large-span structure with an excavation span of $19.2 \mathrm{~m} \sim 23.8 \mathrm{~m}$ (see Figure 9 and Table 5). The metro running tunnel mainly adopts the horseshoe-shaped subterranean excavation form with a single span of $5.8 \mathrm{~m} \sim 6.2 \mathrm{~m}$ for a one-way single lane.

4.1.2. Stratigraphic Features. The stratum distribution along Qingdao Metro from top to bottom includes the Quaternary stratum as well as the strongly weathered, the moderately weathered, and the microweathered (or nonweathered) granite strata. To simplify the analysis and highlight the main points, the Quaternary stratum and the strong weathering stratum were considered soft soil stratum, and the strata in the middle weathering strata and below are considered rock stratum, thus constructing a distribution model for the soil-rock dualistic stratum. The structural characteristics of the dualistic stratum along the two metro lines in Qingdao are shown in Figure 10.

According to the statistical analysis of 3227 geological borehole samples along the two metro lines, the average thickness of the soft soil stratum is $10.2 \mathrm{~m}$; the maximum is $38.0 \mathrm{~m}$; the median is $10.0 \mathrm{~m}$; and the lower and upper quartiles are, respectively, $5.0 \mathrm{~m}$ and $14.8 \mathrm{~m}$ (as shown in Figure 11 and Table 6). Further analysis shows that the number of borehole samples with soft soil stratum thicknesses of $9 \mathrm{~m}$ or less along the metro lines accounts for $45.6 \%$ of the samples; those with less than $12 \mathrm{~m}, 61.4 \%$; those with less than $15 \mathrm{~m}, 77.5 \%$; and those with less than $18 \mathrm{~m}, 89.7 \%$ (as shown in Table 7).

\subsection{Analysis of Metro Tunnel Monitoring Data}

4.2.1. Data Resource. The monitoring data come from six station tunnels of the two metro lines, which have approximately the same section size, excavation depth and technique, support measures, etc. The number of monitoring points, the soft soil stratum thickness $H s$, the rock cover thickness $H r$, and the MRCT-SRS are shown in Table 8. The statistical data are from a third party. The monitoring points for the ground surface settlement are selected within the main area of the tunnel, among which the abnormal points should be excluded in the statistics.

4.3. Inversion Analysis. Table 9 shows that, with regard to the overburden thicknesses exceeding the MRCT-SRS requirements for the stations of Zhiquan Road, Haichuan Road, and Junfeng Road, the average surface settlement is between $2.29 \mathrm{~mm}$ and $6.37 \mathrm{~mm}$, with a maximum value between $6.22 \mathrm{~mm}$ and $12.59 \mathrm{~mm}$, which are small in general. Regarding those for the stations of Zhongshan Park, Jiangxi Road, and Zhanshan Road, the average surface settlement is between $37.5 \mathrm{~mm}$ and $54.75 \mathrm{~mm}$, with a maximum value between $71.54 \mathrm{~mm}$ and $80.96 \mathrm{~mm}$, which are large in general.

Surface settlement can comprehensively reflect the effect of metro construction quality control and the degree of construction influence on the surrounding rock as well as the soil and neighboring environment. For a metro tunnel with shallow buried depth under the approximately same conditions of section size, excavation depth and technique, support measures, etc., the rock cover thickness on the vault meets the MRCT-SRS requirements or not, the surface settlement caused by the tunnel excavation is different by an order of magnitude. This situation fully demonstrates that the self-stability of the surrounding rock has a good correlation with the rock cover thickness (as shown in Figure 12). The rationality of the conclusions obtained in this study has been fully verified.

4.4. Engineering Application. The fundamental goal of an excellent metro line design is to make full use of the selfstability of the surrounding rock and to minimize supplementary engineering measures. Costs should be considered 
TABLE 6: Statistics of the soft soil thickness.

\begin{tabular}{lcccccccc}
\hline Min. $(\mathrm{m})$ & Low position $(\mathrm{m})$ & Lower quartile $(\mathrm{m})$ & Median $(\mathrm{m})$ & Upper quartile $(\mathrm{m})$ & High position $(\mathrm{m})$ & Max. $(\mathrm{m})$ & Average $(\mathrm{m})$ & SD $(\mathrm{m})$ \\
\hline 0.0 & 0.0 & 5.0 & 10.0 & 14.8 & 29.8 & 38.0 & 10.2 & 6.35 \\
\hline
\end{tabular}

TABle 7: Statistical table of the soft soil thickness along lines.

\begin{tabular}{lllllll}
\hline Soil thickness $(\mathrm{m})$ & $\leq 3 \mathrm{~m}$ & $\leq 6 \mathrm{~m}$ & $\leq 9 \mathrm{~m}$ & $\leq 12 \mathrm{~m}$ & $\leq 15 \mathrm{~m}$ & $\leq 18 \mathrm{~m}$ \\
\hline Percentage & $15.6 \%$ & $30.7 \%$ & $45.6 \%$ & $61.4 \%$ & $77.5 \%$ & $89.7 \%$ \\
\hline
\end{tabular}

TABLE 8: Basic overview of metro station tunnel.

\begin{tabular}{|c|c|c|c|c|c|c|c|}
\hline \multirow[b]{2}{*}{$\begin{array}{l}\text { Serial } \\
\text { number }\end{array}$} & \multirow[b]{2}{*}{ Name } & \multirow[b]{2}{*}{$\begin{array}{l}\text { Number of measuring } \\
\text { points (number) }\end{array}$} & \multicolumn{2}{|c|}{$H s(\mathrm{~m})$} & \multicolumn{2}{|c|}{$H r(\mathrm{~m})$} & \multirow[b]{2}{*}{$\begin{array}{l}\text { MRCT-SRS } \\
\quad(\mathrm{m})\end{array}$} \\
\hline & & & $\begin{array}{l}\text { Distribution } \\
\text { range }\end{array}$ & $\begin{array}{l}\text { Mean } \\
\text { value }\end{array}$ & $\begin{array}{l}\text { Distribution } \\
\text { range }\end{array}$ & $\begin{array}{l}\text { Mean } \\
\text { value }\end{array}$ & \\
\hline 1 & $\begin{array}{c}\text { Zhanshan Road } \\
\text { Station }\end{array}$ & 41 & $13.0 \sim 20.5$ & 16.8 & 0.0 & 0.0 & $1.80-2.50$ \\
\hline 2 & $\begin{array}{l}\text { Jiangxi Road } \\
\text { Station }\end{array}$ & 68 & $9.1 \sim 14$ & 11.5 & 0.0 & 0.0 & $1.12-2.10$ \\
\hline 3 & Zhongshan Park & 61 & $8.5 \sim 16.5$ & 11.6 & $0.0 \sim 1.6$ & 0.8 & $1.10-2.25$ \\
\hline 4 & $\begin{array}{l}\text { Junfeng Road } \\
\text { Station }\end{array}$ & 19 & $0.7 \sim 6.8$ & 3.2 & $4.7 \sim 9.8$ & 7.3 & $0.03-0.80$ \\
\hline 5 & $\begin{array}{c}\text { Haichuan Road } \\
\text { Station }\end{array}$ & 28 & $0.8 \sim 8.3$ & 4.3 & $7.0 \sim 11$ & 9.0 & $0.03-0.90$ \\
\hline 6 & $\begin{array}{l}\text { Zhiquan Road } \\
\text { Station }\end{array}$ & 19 & $6.1 \sim 16.5$ & 8.9 & $8.2 \sim 14.3$ & 11.2 & $0.50-0.90$ \\
\hline
\end{tabular}

TABLE 9: Statistical table of ground surface settlement of the station tunnel.

\begin{tabular}{|c|c|c|c|c|c|}
\hline Name & Scope $(\mathrm{mm})$ & $\begin{array}{l}\text { Mean value } \\
(\mathrm{mm})\end{array}$ & $\begin{array}{c}\text { Coefficient of } \\
\text { variation }\end{array}$ & $\begin{array}{l}\text { Standard deviation } \\
(\mathrm{mm})\end{array}$ & $\begin{array}{l}\text { The size relationship between } \mathrm{Hr} \text { and } \\
\text { MRCT-SRS }\end{array}$ \\
\hline $\begin{array}{l}\text { Zhiquan Road } \\
\text { Station }\end{array}$ & $1.37 \sim 6.22$ & 2.29 & 0.36 & 1.18 & $H r>$ MRCT-SRS \\
\hline $\begin{array}{l}\text { Haichuan Road } \\
\text { Station }\end{array}$ & $0.18 \sim 9.97$ & 4.59 & 1.87 & 2.45 & $H r>$ MRCT-SRS \\
\hline $\begin{array}{l}\text { Junfeng Road } \\
\text { Station }\end{array}$ & $2.03 \sim 12.59$ & 6.37 & 2.09 & 3.05 & $H r>$ MRCT-SRS \\
\hline $\begin{array}{l}\text { Zhongshan Park } \\
\text { Station }\end{array}$ & $17.31 \sim 71.54$ & 37.58 & 0.35 & 13.30 & $H r<$ MRCT-SRS \\
\hline Jiangxi Road Station & $16.79 \sim 76.98$ & 46.33 & 0.27 & 12.69 & $H r<$ MRCT-SRS \\
\hline $\begin{array}{l}\text { Zhanshan Road } \\
\text { Station }\end{array}$ & $21.19 \sim 80.96$ & 54.75 & 0.31 & 16.97 & $H r<$ MRCT-SRS \\
\hline
\end{tabular}

only when engineering security is guaranteed. Furthermore, geological risks and construction difficulty should be reduced. The degree to which the surrounding rock can be selfstabilized depends mainly on the distribution conditions of the strata along the metro lines, the understanding of these conditions, and the ability to execute the required tasks. Therefore, the Geologically Easily Stable Area (GSEA) in this study refers to the area that meets the MRCT-SRS requirements for the excavation of the tunnel along the metro in the soil-rock dualistic stratum, otherwise referred to as the Geologically Difficultly Stable Area (GSDA).

The metro station and the running tunnel are considered, respectively, as a single-arch large-span excavation structure with the excavation span of $20.8 \mathrm{~m}$ and a horseshoe-shaped structure with the excavation span of $6.2 \mathrm{~m}$. The buried depth is set at equal intervals of $3 \mathrm{~m}$ falling within the scope of $6 \mathrm{~m} \sim 30 \mathrm{~m}$. Table 10 and Figure 13 show the calculation results of the proportions of the GSEA lengths of the station (considering only 16 subterranean excavation stations) and the running tunnels, respectively, as well as the lengths of the station and the running tunnel of Qingdao's two metro lines under different buried depths.

As the buried depth increases, the proportion of the GSEA in the station tunnel rises first rapidly but then slowly. When the buried depth of the station tunnel is at $6 \mathrm{~m}$, the proportion is $49.2 \%$. When the depth increases to $12 \mathrm{~m}$, the proportion increases rapidly to $76.4 \%$. However, when the depth reaches $18 \mathrm{~m}$, the proportion increase to $90.7 \%$. The change of GSEA with buried depth in running tunnel is similar to that in station tunnel. When the buried 


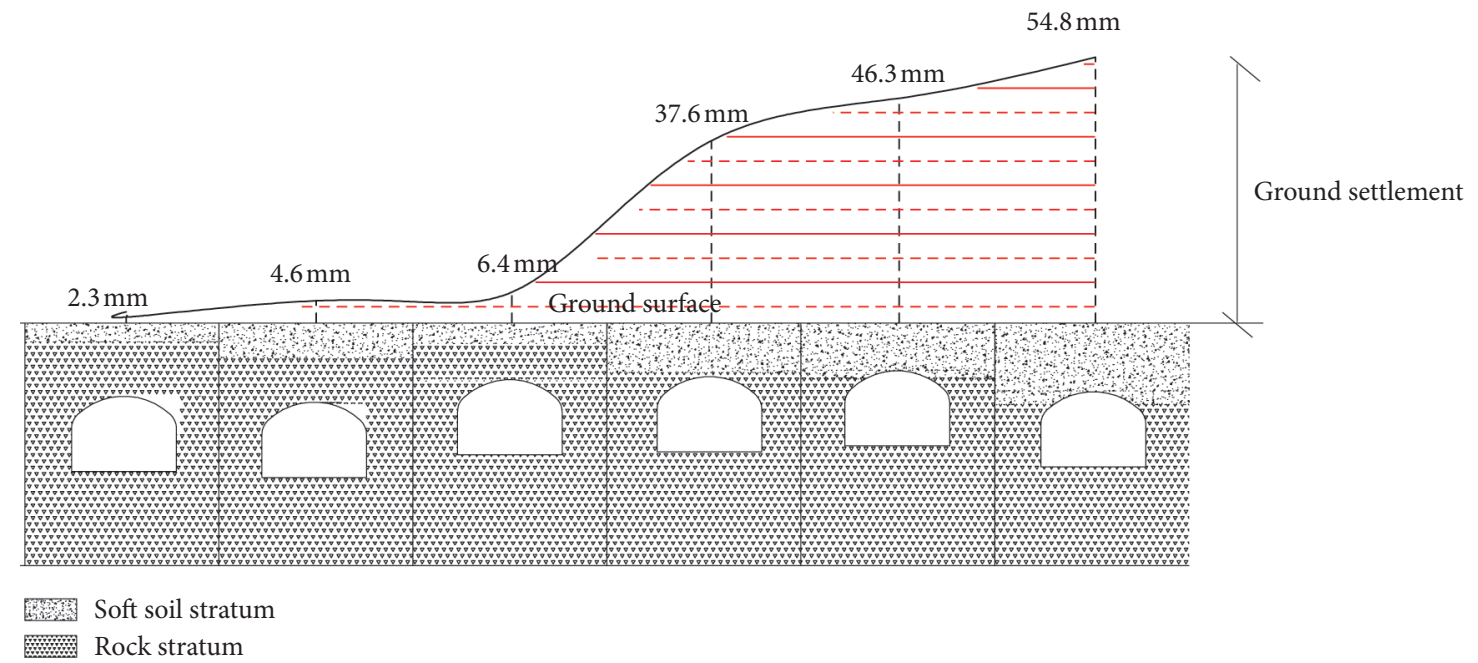

FIgURE 12: The change of ground settlement with different rock cover thicknesses.

TABLE 10: The GSEA ratio of metro tunnel under different buried depths.

\begin{tabular}{lccccccccc}
\hline$H(\mathrm{~m})$ & 6 & 9 & 12 & 15 & 18 & 21 & 24 & 27 & 30 \\
\hline $\begin{array}{l}\text { Station } \\
\text { tunnel (\%) }\end{array}$ & 49.2 & 65.0 & 76.4 & 84.1 & 90.7 & 94.3 & 98.0 & 99.0 & 100.0 \\
$\begin{array}{l}\text { Running } \\
\text { tunel (\%) }\end{array}$ & 26.3 & 40.5 & 57.0 & 71.6 & 87.5 & 93.9 & 96.6 & 98.5 & 99.3 \\
\hline
\end{tabular}

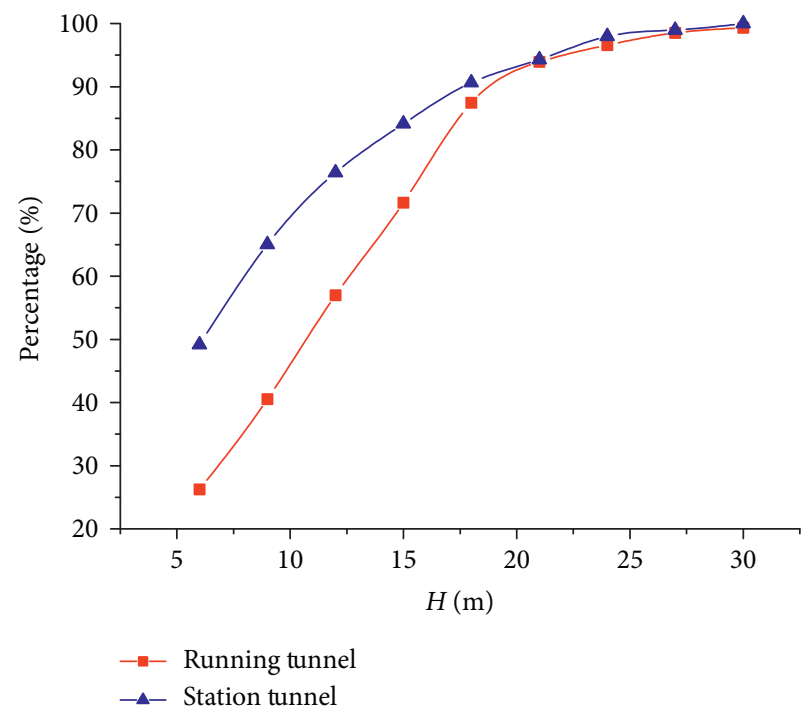

FIGURE 13: GSEA proportion variation for metro tunnel under different buried depths.

depth of the running tunnel is $6 \mathrm{~m}$, the proportion is only $26.3 \%$. However, when the depth increases to $15 \mathrm{~m}$, the proportion rapidly increases to $71.6 \%$. As the depth continues to rise to $18 \mathrm{~m}$, the proportion increases to $87.5 \%$. When the depth reaches $21 \mathrm{~m}$, the proportion slowly increases to $93.9 \%$.

The metro line is mainly composed of the station and the running tunnel. The buried depth of the line depends on the depth of the station tunnel. The depth of the running tunnel is mainly determined by factors such as the buried depth of the station tunnel and the longitudinal slope. The height difference between the station and the running tunnels is set as $12 \mathrm{~m}$. Therefore, when the buried depth of the Qingdao metro station falls within $12 \mathrm{~m} \sim 15 \mathrm{~m}$, the GSEA of the station tunnel accounts for $76.4 \% \sim 84.1 \%$, and the GSEA of the running tunnel accounts for $96.6 \%$ $98.5 \%$.

\section{Conclusion}

(1) The MRCT-SRS of the metro tunnel approximately linearly increases or decreases with respect to the soft stratum thickness $H s$ in the soil-rock dualistic stratum. When the $H s$ is larger, so is the corresponding MRCT-SRS.

(2) The 3D spatial distribution was determined, and the fitted curves were constructed according to the MRCT-SRS, $H s$, and $D$. This facilitated the assessment of the stability of the surrounding rock in the excavation of a metro tunnel.

(3) The variation rule of the Geologically Easily Stable Area with respect to buried depth has been revealed by examining the distribution features of the strata along the Qingdao metro lines. Moreover, the application of the MRCT-SRS in engineering has been expanded to determine the reasonable buried depth of the metro line.

\section{Data Availability}

The data used to support the findings of this study are available from the corresponding author upon request.

\section{Conflicts of Interest}

The authors declare that they have no conflicts of interest. 


\section{Authors' Contributions}

Ziguang Zhang was in charge of the paper and completed the construction of thesis framework system and thesis writing. Tao $\mathrm{Xu}$ and Xiaofeng Liu were responsible for the collection, sorting, and analysis of relevant project case data in this paper. Guangyong Cao completed the related work of numerical calculation in this paper.

\section{Acknowledgments}

This study was funded by the Scientific Research Project of Anhui Jianzhu University (no. 2019QDZ24) and Science and Technology Support Project of Anhui Sijian Holding Group Co., Ltd. (no. HYB20190126).

\section{Supplementary Materials}

Figures and Tables of Survey Data in Measurements. (Supplementary Materials)

\section{References}

[1] K. G. Sun, W. P. Xu, W. G. Qiu, H. B. Li, Q. Y. Xianand, and T. Li, "Study on the characteristics of safety distribution changing with buried depth for metro station in upper-soft and lower-hard stratum," Advances in Civil Engineering, vol. 2018, Article ID 6047919, 14 pages, 2018.

[2] Y. L. Shang, S. J. Du, T. Y. Han, and B. Shao, "Case study on deformation control of upper-soft and lower-hard large span tunnel station using combined control technology and monitoring demonstration," Sains Malaysiana, vol. 46, no. 11, pp. 2091-2099, 2017.

[3] T. J. Liu, S. Y. Zheng, X. W. Tang, and W. X. Xu, "Experimental study on seismic response of a large-span and columnfree subway station in composite strata," Shock and Vibration, vol. 2019, Article ID 8412390, 15 pages, 2019.

[4] R. H. Lv, "On adaptability assesment of a TBM used in urban subways," Modern Tunnelling Technology, vol. 54, no. 1, pp. 31-39, 2017.

[5] J. B. Wang, Q. Huo, Z. P. Song, and Y. W. Zhang, "Study on adaptability of primary support arch cover method for largespan embedded tunnels in the upper-soft lower-hard stratum," Advances in Mechanical Engineering, vol. 11, no. 1, pp. 1-15, 2019.

[6] X. L. Yang and H. B. Xiao, "Safety thickness analysis of tunnel floor in karst region based on catastrophe theory," Journal of Central South University, vol. 23, no. 9, pp. 2361-2367, 2016.

[7] B. S. Xu, S. C. Li, R. C. Liu, and C. L. Zhao, "Study on the reasonable cover thickness of a subsea tunnel with the numerical calculation criterion method," in Proceedings of the 4th geo-China International Conference: Emerging Technologies in Tunnel Engineering, Modeling, Design, Construction, Repair, and Rehabilitation, pp. 81-91, Shandong, China, July 2016.

[8] X. D. Wang, Y. Yuan, X. Wu, and Z. Du, "Study on method to determining the ration depth of metro station in composed of soil and weathered rock stratum," in Proceeding of the 6th European Congress on Computational Methods in Applied Sciences and Engineering, Vienna, Austria, September 2012.

[9] X. B. Qiu, S. C. Li, and W. Z. Chen, "Numerical analysis of rock cover thickness of subsea tunnel," Tunnelling and Underground Space Technology, vol. 19, p. 426, 2004.
[10] Z. G. Zhang, K. G. Sun, and W. G. Qiu, "Reasonable thickness of metro station with single arch large-span in upper-soft and lower-hard stratum," International Conference on Mechanics and Architectural Design, vol. 2016, no. 5, pp. 72-82, 2016.

[11] W. Wang, M. J. Hu, H. W. Zhang, and X. M. Zhang, "Conversion timing of tunnel excavation methods in uppersoft and lower-hard stratum based on displacement direction angle theory," International Journal of Geomechanics, vol. 19, no. 4, Article ID 05019003, 2019.

[12] R. Thom and D. H. Fowler, Structural Stability and Morphogenesis, Benjamin-Addison Wesley, New York, NY, USA, 1975.

[13] J. M. T. Thompson and E. C. Zeeman, "Classification of elementary catastrophes of codimension $\leq 5$, structural stability , the theory of catastrophes and applications in the sciences," Lecture Notes in Mathematics, vol. 525, pp. 263-327, SprigerVerlag, Berlin, Germany, 1976.

[14] E. C. Zeeman, "Bifurcation,catastrophes and turbulence," New Directions in Applied Mathematics, pp. 105-153, SprigerVerlag, New York, NY, USA, 1982.

[15] T. Poston and I. Stewart, Catastrophe Theory and its Application, Pitman, London, UK, 1978.

[16] C. C. Xia, C. B. Xu, and X. Zhao, "Study on the strength reduction DDA method and its application to mountain tunnel," International Journal of Computational Methods, vol. 9, no. 3, Article ID 1250041, 2012.

[17] S. Ren, Z. Wang, D. Y. Jiang, and C. Liu, "Study on the catastrophe model of the surrounding rock and simulating the constructing process by DEM in gonghe tunnel," in Proceedings of the 2013 Third International Conference on Intelligent System Design and Engineering Applications, pp. 1355-1357, Hong Kong, China, January 2013.

[18] T. T. Wang, X. Z. Yan, H. L. Yang, and X. J. Yang, "Stability analysis of the pillars between bedded salt cavern gas storages by cusp catastrophe model," Science China.Technological Sciences, vol. 54, no. 6, pp. 1615-1623, 2011.

[19] C. P. Zhang and K. H. Han, "Collapsed shape of shallow unlined tunnels based onfunctional catastrophe theory," Mathematical Problems in Engineering, vol. 2015, Article ID 681257, 13 pages, 2015.

[20] Y. J. Zhou, X. D. Xu, X. T. Li, M. Li, and Y. G. Yang, "Study on catastrophe instability of support system in gypsum goaf based on energy dissipation theory," Advances in Civil Engineering, vol. 2018, Article ID 4293584, 9 pages, 2018.

[21] R. Zhang, H. B. Xiao, and W. T. Li, "Functional catastrophe analysis of collapse mechanism for shallow tunnels with considering settlement," Mathematical Problems in Engineering, vol. 2016, Article ID 4820716, 11 pages, 2016.

[22] X. L. Huang and R. Zhang, "Catastrophe stability analysis for shallow tunnels considering settlement," Journal of Central South University, vol. 25, no. 4, pp. 946-960, 2018.

[23] M. A. Ghorbani, R. Khatibi, B. Sivakumar, and L. Cobb, "Study of discontinuities in hydrological data using catastrophe theory," Hydrological Sciences Journal-Journal des Sciences Hydrologiques, vol. 57, no. 7, pp. 1137-1151, 2010.

[24] X. P. Zheng, J. H. Sun, and Y. Cheng, "Analysis of crowd jam in public buildings based on cusp-catastrophe theory," Building and Environment, vol. 45, no. 8, pp. 1755-1761, 2010.

[25] Y. Tao, J. Cao, J. M. Hu, and Z. C. Dai, “A cusp catastrophe model of mid-long-term landslide evolution over low latitude highlands of China," Geomorphology, vol. 187, pp. 80-85, 2013. 
[26] B. Hu and N. Xia, "Cusp catastrophe model for sudden changes in a person's behavior," Information Sciences, vol. 294, pp. 489-512, 2015.

[27] J. C. Xu and Y. D. Ni, "Prediction of grey-catastrophe destabilization time of a granite residual soil slope under rainfall," Bulletin of Engineering Geology and the Environment, vol. 78 , no. 8 , pp. 5687-5693, 2019.

[28] Y. M. Tian, B. Zheng, H. L. Shen, S. N. Zhang, and Y. R. Wang, "A novel index based on the cusp catastrophe theory for predicting harmful algae blooms," Ecological Indicators, vol. 102, pp. 746-751, 2019.

[29] S. W. Ma, Z. Q. Luo, J. H. Hu, Q. F. Ren, Y. G. Qin, and L. Wen, "Determination of intervening pillar thickness based on the cusp catastrophe model," Advances in Civil Engineering, vol. 2019, Article ID 8253589, 11 pages, 2019.

[30] J. L. Qiu, Y. L. Xie, and H. B. Fan, "Centrifuge modelling of twin-tunnelling induced ground movements in loess strata," Arablan Journal of Geosciences, vol. 10, no. 22, pp. 1251713017, 2017.

[31] J. X. Lai, X. L. Wang, J. L. Qiu, J. X. Chen, Z. N. Hu, and H. Wang, "Extreme deformation characteristics and countermeasures for a tunnel in difficult grounds in southern Shaanxi, China," Environmental Earth Sciences, vol. 77, no. 19, p. 14, 2018. 